\title{
Lateral force-displacement response of buried pipes in slopes
}

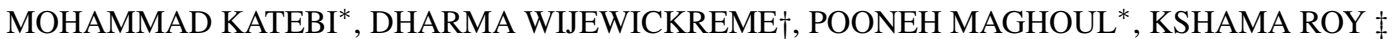

\begin{abstract}
A series of full-scale experiments were conducted to estimate lateral soil constraints on the pipes buried in dense sandy slopes at different burial depths. The experimental data indicated that the soil force on the pipe increases with increasing the slope grade and burial depth ratio. The lateral soil force versus relative pipe displacement response observed from the experiments is presented and compared to those arising from level ground conditions. The study was extended to larger burial depth ratios by simulating pipes under sloping ground conditions using a numerical (finite element) model that was initially calibrated using the results from physical modelling. The findings from the study in terms of the variation of peak lateral soil restraint as a function of the slope grade and burial depth ratio are presented for consideration in pipeline design.
\end{abstract}

KEYWORDS: Buried structures; Finite-element modelling; Full-scale tests; Pipes \& pipelines; Slopes; Soil/structure interaction

\section{INTRODUCTION}

In the current design practice, the response of pipelines subjected to ground movements is typically investigated using numerical techniques such as the finite element (FE) method in which the soil-pipe interaction is modelled using a series of orthogonal discrete soil springs (PRCI, 2017; ALA, 2005). The analysis of a given soil-pipe interaction scenario is typically undertaken considering non-linear soil springs in three orthogonal directions: lateral (horizontal), vertical (bearing and uplift) and, longitudinal (axial). The force-displacement curves of these soil springs, also commonly called p-y curves, are intended to describe the soil force development as a function of relative soil-pipe displacements.

To establish benchmarks for presenting the results and compare with cases involving different pipe sizes and depths, the concept of dimensionless load and normalised displacement has been used to interpret soil forces on pipelines. As previously suggested by Hansen (1961) and used by Audibert and Nyman (1978); Rowe and Davis (1982); Trautmann (1983); Burnett (2015), the dimensionless horizontal load per unit length of pipe $\left(\bar{F}_{h}\right)$ is expressed using the relationship given in Eq.1. The normalised horizontal displacement of the pipe $(\bar{Y})$ during the soil-pipe interaction in cohesionless soil is defined according to Eq.2.

$$
\bar{F}_{h}=F_{h} /\left(\gamma^{\prime} H D\right)
$$

$$
\bar{Y}=Y / D
$$

\footnotetext{
Manuscript received. .

* Department of Civil Engineering, University of Manitoba, Winnipeg, MB, R3T 5V6, Canada

$\dagger$ Department of Civil Engineering, University of British Columbia,

Vancouver, BC, V6T 1Z4, Canada

$\ddagger$ Northern Crescent Inc., Calgary, Alberta, T2P 0W5, Canada
}

where $F_{h}$ is the horizontal load per unit length of pipe, $H$ is the vertical distance from the centre of the pipe to the ground surface, $D$ is the outside diameter of the pipe, $\gamma^{\prime}$ is the effective unit weight of soil, and $Y$ is the transverse pipe displacement.

In the current design guidelines (e.g. ALA, 2005; PRCI, 2017), the peak value of the dimensionless horizontal load per length $\left(\bar{F}_{h}\right)$ is termed the lateral soil restraint $\left(N_{\mathrm{qh}}\right) . N_{\mathrm{qh}}$, which essentially represents a horizontal "bearing capacity factor", depends on the internal friction angle of soil $\left(\phi^{\prime}\right)$ and the pipeline centreline depth $(H)$ to diameter (D) ratio, $\zeta=H / D$ (burial depth ratio). The displacement at the peak load $\left(Y_{P}\right)$ for laterally loaded pipes under level ground conditions can be estimated using Eq. 3 according to PRCI 2017.

$$
Y_{\mathrm{p}}=0.04(H+0.5 D) \leq 0.1 D \text { to } 0.15 D
$$

The value of $N_{\mathrm{qh}}$ has been primarily developed to address the cases of buried pipeline in level ground based upon bearing capacity mechanics considerations supported by experimental data. As mentioned previously, the force-displacement curves for the soil springs are developed initially based on the underlying assumption that the ground surface is perfectly horizontal. However, pipelines often cross natural slopes or riverbanks, where the ground surfaces are inclined. Therefore, there is a need for a comprehensive investigation to assess the effects of slope grade on pipeline design.

It is important to recognise that the soil-pipe interaction mechanism is entirely different within the sliding area and outside the landslide due to the manner in which the ground deformation mechanisms are mobilised. With this background, a comprehensive investigation was undertaken to study the significant effect of the ground inclination (i.e. slope grade) on soil-pipe interaction. Two types of experiments were designed to address the soil-pipe interaction both in the sliding area and the area outside the landslide as shown in Fig. 1. In the first 
type, to model the lateral soil-pipe interaction within the sliding area, the pipe was horizontally pulled toward the crest of the slope as shown by the red arrow marked "B" in Fig. 1b. In the other type, the pipe was horizontally pulled toward the toe of the slope as shown by the red arrow marked "B" in Fig. 1c to investigate the lateral soil-pipe interaction outside the landslide area. The experiments were performed at the Advanced Soil Pipe Interaction Research (ASPIRe ${ }^{\mathrm{TM}}$ ) full-scale testing facility at the University of British Columbia, Vancouver, Canada. The full-scale experiments for physical modelling of soil-pipe interaction under close-to-field conditions with precision instruments provided the opportunity to investigate the mechanics of the problem and generate valuable data for calibration/validation of numerical models. The experimental data was then used to develop calibrated FE simulations and study the problem numerically, considering various combinations of slope grades and burial depth ratios. The study aims to characterise soil springs as a function of slope grade and burial depth ratio in dense sands.

This paper is organised as follows: the literature is reviewed to provide a background of research studies on lateral soilpipe interaction. The testing program, equipment, soil and pipe material properties, and the details on the test preparation are described. The force-displacement response from the experimental work is presented and discussed. A FE model is developed to investigate the peak lateral soil restraint for both shallow and deep embedment conditions. The FE modelling procedure, soil model, and calibration of the FE model with the physical experiment conducted in the present study are explained. Finally, the variation of $N_{\mathrm{qh}}$ as a function of slope grade and burial depth ratio is presented graphically for consideration in pipeline design.

\section{BACKGROUND}

The early evaluation of pipeline response subject to lateral soil displacement was based upon published studies on anchor plates, retaining walls, and laterally loaded piles (Hansen, 1961; Smith, 1962; Ovesen, 1964; Kostyukov, 1967; Ovesen and Strømann, 1972; Neely et al., 1973; Das and Seeley, 1975; Murray and Geddes, 1989). The first well-known experimental study of soil restraint on buried pipes was carried out by Audibert and Nyman (1978). They performed a series of smallscale tests on 25,60 , and $114-\mathrm{mm}$ diameter pipes both in loose and dense sands. The experimental results were validated against a field test conducted on a $230-\mathrm{mm}$ diameter pipe. The study covered a wide range of burial depth ratios, $\zeta=1.5$ to 24.5, and the results were in good agreement with those of Hansen (1961) and Das and Seeley (1975).

Trautmann and O'Rourke (1985) performed a series of fullscale experiments to study the lateral soil restraint of buried pipes. The tests were performed in loose, medium, and dense sands (corresponding to friction angles of $31^{\circ}, 36^{\circ}$, and $44^{\circ}$ ) with the burial depth ratio $(\zeta)$ ranging from 1.5 to 11 . A good agreement was observed compared to the analytical solution of Rowe and Davis (1982) when the sand was medium or dense. However, the soil restraint in the tests with loose sands was higher than that of the analytical solution. Their work was used in ASCE (1984) and ALA (2005) guidelines for the estimation of lateral soil springs.

The soil-pipe interaction is typically simulated using the soil-restraint springs aligned with the longitudinal axis (axial) of the pipeline and two directions orthogonal to it (vertical and horizontal). Nyman (1984) studied the soil restraint in the oblique (horizontal-vertical) direction through a series of fullscale tests. A method was proposed based on the peak uplift and horizontal soil restraints and the oblique loading angle for estimating the oblique force-displacement relationship. Hsu (1996) performed an extensive experimental study on the oblique soil restraint. Several parameters, including the pipe diameter, loading rate, burial depth ratio, and loading angle, were investigated. The hyperbolic equations, initially proposed by Kondner (1963), were modified for the estimation of the oblique soil restraint. Hsu et al. (2001) and Hsu et al. (2006) performed a series of full-scale experiments on loose and dense sands to measure the oblique soil restraint in the axial-horizontal direction. They concluded that the axial and horizontal soil loads on the oblique pipes could be calculated by multiplying the corresponding cosine and sine values of the oblique angle with the associated longitudinal soil load of axial pipe and the horizontal soil load of the lateral pipe, respectively.

Yimsiri et al. (2004) calibrated a numerical model against the experiments of Trautmann (1983). They used the model to study uplift and horizontal soil spring for burial depth ratios $(\zeta)$ up to 100 . The results were presented graphically for different values of $\zeta$ and $\phi^{\prime}$, and incorporated in ALA (2005). Calvetti et al. (2004) studied the soil-pipe interaction using a small scale $1 \mathrm{~g}$ physical model with different tube diameter and depth. A distinct element method was calibrated with the experiential data and used to study different loading directions $\left( \pm 90^{\circ}\right.$ with respect to horizontal) on the drag force. O'Rourke et al. (2005) performed a series of centrifuge modelling to determine the strain in a pipe induced by permanent ground deformation. They constructed a beam-type finite element model using the soil springs in the longitudinal and horizontal directions and defined the soil springs based upon the recommendations by ASCE (1984). A good agreement was observed between the experimental data and the numerical models except for the axial strain, which was less in the physical tests compared to the simulation results. di Prisco and Galli (2006) studied the soil-pipe interaction using small-scale physical tests and numerical analysis focusing on the loading direction, soil density and depth ratio. Strong coupling was reported between the horizontal and vertical components of force when the pipe was pulled in different inclined loading directions. The longitudinal force was found independent of the other loading components. 
Daiyan et al. (2011) performed a series of centrifuge modelling as well as a numerical study on oblique (axiallateral) soil-pipe interaction. They found that the peak values of the axial and lateral soil restraints are a function of the relative soil-pipe movement's attack angle. Tian and Cassidy (2011) performed a series of lateral soil-pipe interaction tests in calcareous sands. They reported that the berms built up alongside a pipe in large displacement can affect the forcedisplacement behaviour of soil-pipe interaction. They presented a new hardening relationship for the soil-pipe interaction model, calibrated against 20 geotechnical centrifuge tests, to account for horizontal displacement hardening of the yield surface. Farhadi and Wong (2014) studied the soil-pipe interaction for buried pipes in clay and sand for oblique loading using numerical modellings. Several factors such as soil parameters (e.g. dilation angle, soil cohesion, friction angle), burial depth ratio, soil-pipe interaction coefficient and loading direction were investigated to assess their effects on the maximum soil resistance against pipe movements.

Robert et al. (2016) calibrated a three-dimensional finite element model with the results of large-scale tests. The numerical model was used to study the pipeline behaviour in strike-slip fault movements in dry and partially saturated sand. The analysis was extended by changing soil parameters (e.g., soil type, density and moisture content), pipe parameters (e.g., pipe material and depth) and fault inclination to investigate their effects on pipe load and deformation. A numerical model was calibrated by Jung et al. (2016) with results from largescale tests in dry and partially saturated sand for lateral and uplift movements of pipe. This numerical model was used to characterise the force-displacement relations of soil-pipe interaction for lateral, uplift, bearing and oblique directions. The force-displacement relations were used in an analytical approach to estimate the effects of strike-slip fault on a buried pipe. It was shown that the analytical results compare well with test results on 250 and $400 \mathrm{~mm}$ diameter high-density polyethylene pipes in partially saturated sand.

A series of full-scale physical model testing was undertaken by Wijewickreme et al. (2017) to evaluate this complex soil-pipe interaction problem by testing the performance of the $400-\mathrm{mm}$ diameter (nominal pipe size, NPS 16) pipe specimens buried in moist sands and crushed limestone trench backfill. The oblique soil restraint values were found to depend significantly on the internal friction angle $\left(\phi^{\prime}\right)$ of soil when the pipe movement was closer to the horizontal axis; whereas, the soil restraint was less sensitive to $\phi^{\prime}$ when the oblique movement was higher than about $35^{\circ}$ with respect to the horizontal axis. Zhang and Askarinejad (2019) studied the lateral soil forces acting on the buried pipes subject to slope instabilities by conducting a series of small-scale tests in a centrifuge testing facility. They performed six tests on dense coarse sands and two tests on medium-dense fine sands. The force-displacement relationships of lateral soil-pipe interaction were derived and compared to previous studies performed on flat ground conditions. They proposed a geometric factor that 216 links the ultimate soil load in sandy slopes to that in the 217 flat ground. Katebi et al. (2019) conducted a real-case study 218 of three pipelines subjected to landslides. They implemented 219 a one-dimensional beam-type FE model with soil springs. 220 The ground displacements, monitored over five consecutive 221 years, were imposed on the pipe through soil springs, defined 222 using PRCI (2017). The results from the simulations were 223 compared to those from the instrumentation in order to 224 evaluated the pipeline performance in a comprehensive manner. 225 Morshed et al. (2020) studied the soil-pipe interaction in dense 226 sand using finite element modelling considering the pre-peak 227 hardening, post-peak softening, density and confining pressure- 228 dependent behaviour of sand. A variety of loading directions 229 ranging from vertical upward to lateral (horizontal) were 230 simulated. A simplified approach was presented to estimate the 231 maximum oblique resistance based on the maximum vertical 232 and lateral resistance.

a)

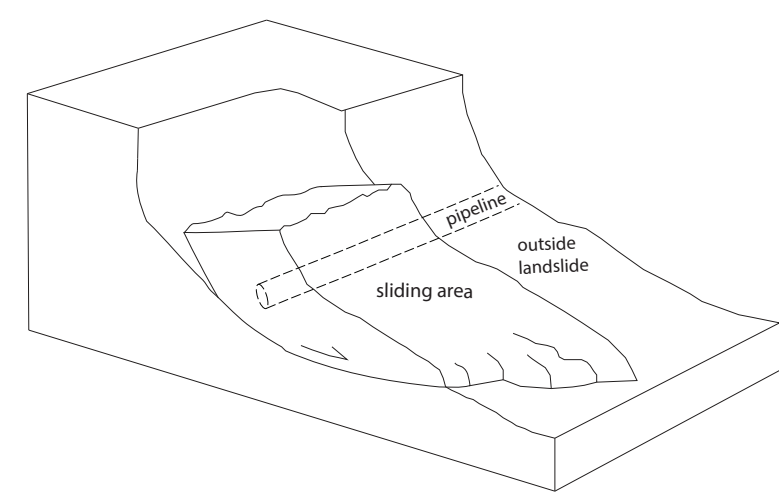

b) within sliding area c) outside landslide
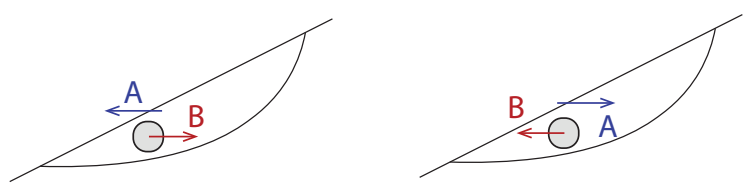

A: direction of soil displacement relative to pipe

$\mathrm{B}$ : direction of pipe loading in the experiments

Fig. 1. Schematic view of soil-pipe interaction: (a) pipes subject to a landslide; (b) soil-pipe interaction within the sliding area; (c) soil-pipe interaction outside the landslide area

\section{EXPERIMENTAL STUDY}

In this section, the testing equipment is briefly explained, 234 and some critical aspects of the full-scale experiments are 235 presented. The reader is encouraged to read previous studies 236 including Karimian (2006), Wijewickreme et al. (2009), 237 Monroy-Concha (2013), and Katebi et al. (2020) for further 238 information on the equipment. 
Testing program

A total of 10 full-scale experiments (detailed in Table 1) are conducted in this research program to investigate the influence of $\zeta$ and $\vartheta$ (where $\vartheta=\tan (\beta)$, in which $\beta$ is the slope angle and $\vartheta$ is the slope grade, as shown in Fig. 2b) on lateral soil-pipe interaction. As may be noted, the experiments were performed to simulate both positive and negative slope situations with respect to pipe movements. In the experiments, the pipe is subjected to displacement-controlled lateral loading conditions at a constant displacement rate of $2.5 \mathrm{~mm} / \mathrm{sec}$. The same displacement rate was used in the lateral soil-pipe interaction testing performed by Karimian (2006) with the same sand backfill, after showing that the test results were not sensitive to the loading rates between 2 and $50 \mathrm{~mm} / \mathrm{sec}$. Therefore, the chosen rate is considered reasonable for the present testing program.

\section{Table 1. Summary of experiments}

\begin{tabular}{|c|c|c|c|c|c|}
\hline Test \# & $\zeta$ & $\vartheta$ & Test \# & $\zeta$ & $\vartheta$ \\
\hline 1 & 1.6 & $25 \%$ & 6 & 2.4 & $-40 \%$ \\
2 & 1.6 & $40 \%$ & 7 & 2.4 & $-25 \%$ \\
3 & 2.0 & 0 & 8 & 2.4 & 0 \\
4 & 2.0 & $25 \%$ & 9 & 2.4 & $25 \%$ \\
5 & 2.0 & $40 \%$ & 10 & 2.4 & $40 \%$ \\
\hline
\end{tabular}

\section{Testing equipment}

The testing equipment comprises a $3.8 \mathrm{~m} \times 2.5 \mathrm{~m} \times 2.5 \mathrm{~m}$ steel-frame soil chamber, built for soil-pipe interaction studies in axial, horizontal, vertical, and oblique directions. The details of the facility are shown in Fig. 2 through several photos. The plan and lateral view of the equipment are provided in Fig. 3 with the identification numbers listed in Table 2. This unique setup enables the user to simulate both positive and negative slope situations with respect to pipe movements, as illustrated in Fig. 3(b).

The facility is equipped with two hydraulic actuators with an individual actuator capacity of $418 \mathrm{kN}$. These actuators were positioned on the south side of the chamber (Note: the longer dimension of the chamber is parallel to the north-south direction), and they are connected using 50-mm steel cables to the two ends of the test pipe segment laterally placed in the east-west direction as shown in Fig. 3(b). Soil forces and pipe movements were measured using two load cells and two string potentiometers. The load cells had an individual capacity of $250 \mathrm{kN}$ and were installed on the actuator cylinders. The string potentiometers were positioned on a steel frame structure on the north side of the chamber and connected to the pipe using an 80-cm-long extension wire passing through a small hole on the north wall of the chamber.

The walls of the chamber are made of treated plywood stiffened with timber cross-beams. The interface friction between the soil and vertical sidewalls of the soil chamber during lateral pipe movements were minimised by having the west side wall lined with stainless steel sheets and the east side (front) wall with Plexiglas materials (i.e., which would also 28 promote low interface friction with soil). The chamber sidewall 286 friction force on the pipe was reported to be less than $2 \%$ of 287 the measured peak lateral soil restraint according to Karimian 288 (2006). The dimensions of the chamber and size/position of 289 the pipe were chosen such that the shear failure surface does 290 not interfere with the chamber walls. The thickness of the pipe 291 wall was selected so that the assumption of a rigid pipe would 292 be reasonable under the applied loads-in turn, to enable the 293 assumption of a plane strain soil deformation mechanism (with respect to the north-south vertical plane).

Table 2. Description of the testing equipment (identification in Fig. 3)

\begin{tabular}{|l|l|l|l|}
\hline$\#$ & Description & $\#$ & Description \\
\hline 1 & Servo controller & 15 & Desk \\
2 & Hydraulic actuator & 16 & Control system \\
3 & LVDT & 17 & Data acquisition system \\
4 & Hydraulic cylinder & 18 & Laptop for data acquisition \\
5 & Load cell & 19 & Laptop for Controller \\
6 & Plywood wall & 20 & 500 W Halogen work light \\
7 & Foam & 21 & Matte black tarp \\
8 & 25-mm Steel cable & 22 & Camera \\
9 & Plexiglass wall & 23 & Loading pedestal \\
10 & Stainless steel & 24 & Steel foundation \\
11 & Pipe & 25 & Soil surface (flat ground) \\
12 & 80-cm extension wire & 26 & Soil surface (positive slopes) \\
13 & Access hole & 27 & Soil surface (negative slopes) \\
14 & String potentiometer & 28 & Steel stand for string pot \\
\hline
\end{tabular}

Soil and pipe materials

The experiments were performed using Fraser River sand as the backfill material. This sand is dredged from Fraser River in the Lower Mainland of British Columbia in Canada. It has wide usage in the construction sector and been used for geotechnical engineering research test materials at UBC for more than thirty years. The sand has an average particle size $\left(D_{50}\right)$ of 0.26 $\mathrm{mm}$; coefficient of uniformity $\left(C_{\mathrm{u}}\right)$ of 1.6 , which classifies the sand as uniformly graded (Fig. 4). Its specific gravity $\left(G_{\mathrm{s}}\right)$ is 2.71 , with the minimum and maximum void ratios $\left(e_{\min }\right.$ and $e_{\max }$ ) of 0.62 and 0.94 , respectively (Karimian, 2006). The sand particle sphericity is low to medium, and its angularity is from angular to sub-rounded (Garrison et al., 1969). Fraser River sand is composed of $40 \%$ quartzite and chert, $11 \%$ feldspar, $45 \%$ unstable rock fragments (mostly fragments of volcanic rocks), and $4 \%$ other minerals (Garrison et al., 1969). The maximum dry density of the sand at the optimum water content of $19.5 \%$ is $1625 \mathrm{~kg} / \mathrm{m}^{3}$. The water content of the sand used 313 in the experiments was below $2 \%$. Further information on the 314 geotechnical characteristics of Fraser River sand can be found 315 in Uthayakumar (1996), Sivathayalan (2000), and Karimian 316 (2006). 


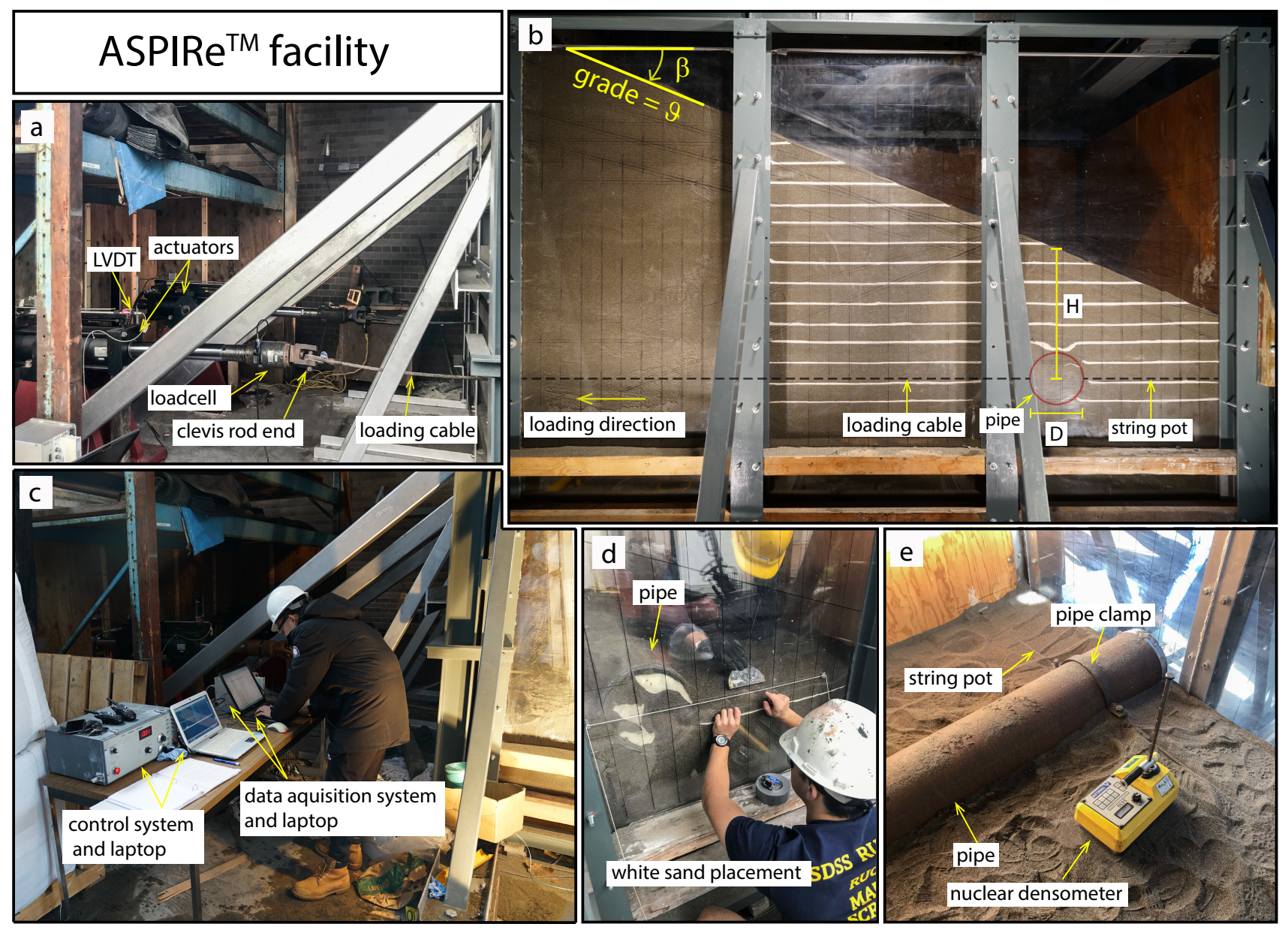

Fig. 2. Advanced Soil-Pipe Interaction Research facility at the University of British Columbia: (a) actuators; (b) test configuration; (c) electronics; (d) white sand placement; (e) pipe position

A steel pipe segment with an outside diameter of $324 \mathrm{~mm}$ (Nominal Pipe Size, NPS 12), the wall thickness of 6.35 $\mathrm{mm}$ (Schedule 20), and length of $2.4 \mathrm{~m}$ was used for the experimental study. The pipe had a rusty uncoated sand-blasted surface.

\section{Test chamber preparation}

The preparation of the test chamber was carried out in three steps. First, the soil was deposited in 15 -cm lifts and compacted with a static roller to reach the invert elevation of the pipe. The pipe was then placed on the sand bed, and connections to the actuators and string potentiometers were made. The pipe was plugged from both ends with the use of wooden caps and silicone caulk to prevent potential ingress of sand particles into the pipe cavity. Next, the filling was resumed to reach the desired burial depth ratio. The soil compaction was performed with a tamper in the vicinity of the chamber boundaries and pipe. The total unit weight of soil was targeted at $\gamma=16 \mathrm{kN} / \mathrm{m}^{3}$. The soil density was measured using metallic bowls of known volumes located at three arbitrary points in each layer; the bowls were buried in each layer before the compaction and excavated after the compaction. The unit weight was calculated by weighting the bowls before and after the process. These values were cross-checked with nuclear densitometer measurements, with the density measurements between the two methods resulting in values within $2 \%$ of each other. In the tests involving sloping ground, the soil above the desired line of the ground surface was carefully excavated by hand to create the required slope. After completing a given test, the soil was emptied using a $30 \mathrm{~cm} \times 45 \mathrm{~cm}$ opening in the northern wall of the soil chamber. A conveyor belt, aligned immediately below this opening, was used to transfer the soil to bulk bags for storage and later usage.

\section{LATERAL SOIL RESTRAINTS: EXPERIMENTAL FORCE-DISPLACEMENT RESPONSE}

The force-displacement response of soil-pipe interaction is examined in a dimensionless form as defined in Eq. 1 and 35 Eq. 2. From a quality control point of view, an initial test with 352 a level ground surface was performed for comparing the results 353 of the current experimental setup with respect to a similar test 354 previously performed by Monroy-Concha (2013). The results 355 from the two tests are compared in Fig. 5, and showing a very 356 good agreement, thus confirming the repeatability of the testing 357 methodologies employed at the ASPIRe ${ }^{\mathrm{TM}}$ testing facility. 358 

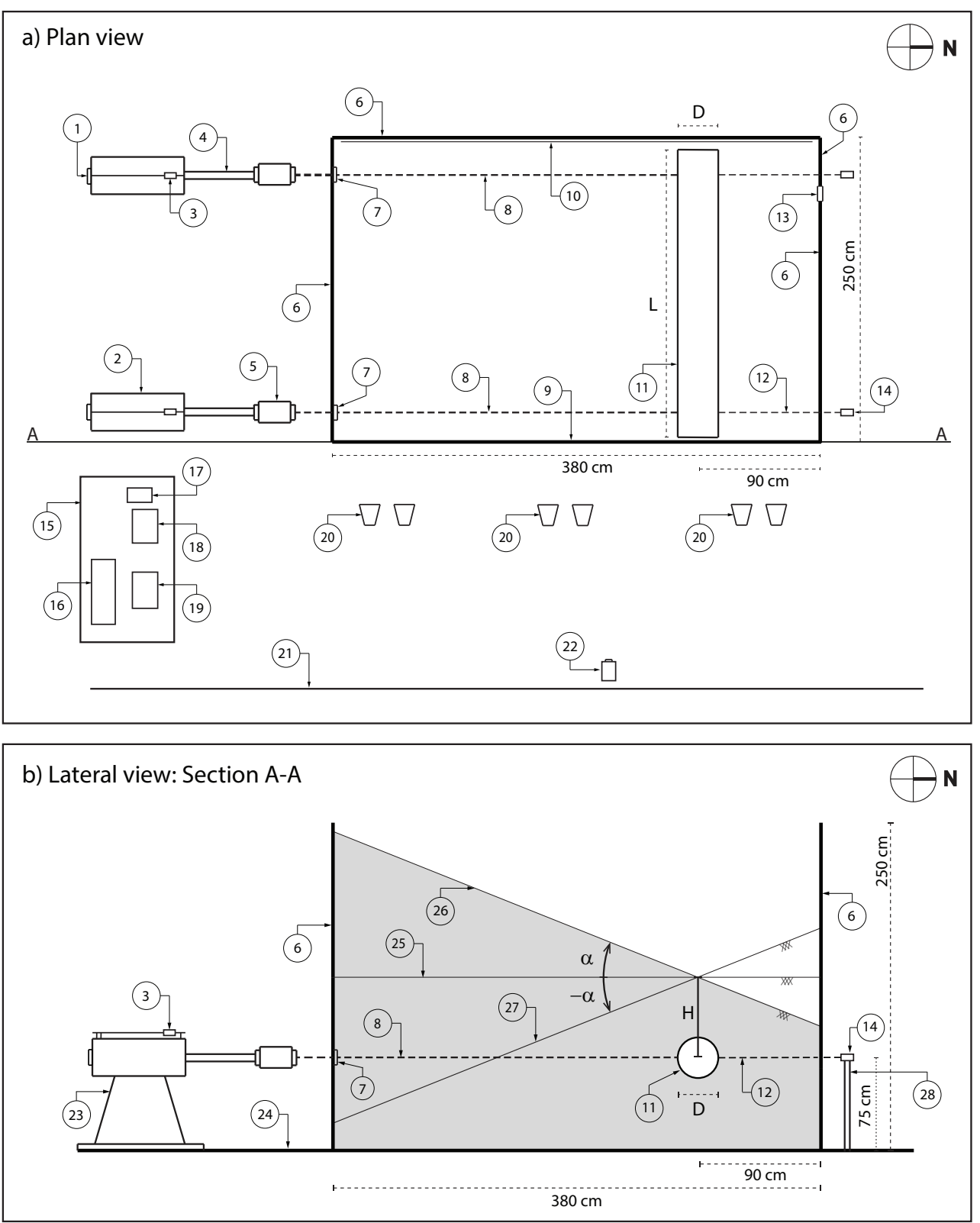

Fig. 3. Plan and lateral view of the testing equipment-identification is described in Table 2

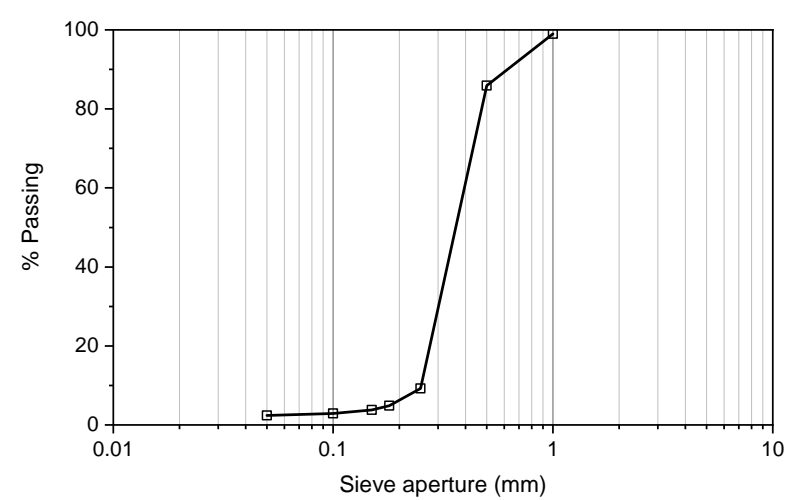

Fig. 4. Grain size distribution of Fraser River sand
The response of soil-pipe interaction in the form of $\bar{F}_{h}-\bar{Y} \quad 359$ for all the ten experiments is presented in Fig. 6 with the 360 use of solid lines; each sub-figure, denoted 6(a) through 6(d), 361 corresponds to a specific $\zeta$ value. Note that the pipe load 362 values presented in this work have been corrected for the soil- 363 cable frictional load. This is achieved based on the results of 364 an independent test conducted by Karimian (2006) on a 2-m- 365 free-end cable with soil cover of $1.12 \mathrm{~m}$. The soil-cable load 366 is calculated for each test, assuming that it is proportional 367 to the soil cover and cable length. It is important to note 368 that the pipe gradually moves upward during a test, and as 369 such, the direction of the pulling cables gradually deviates 370 from horizontal with increasing displacement. The deviation 371 of the loading cables from the initial level is negligible for 372 $\bar{Y}<0.3$ and essentially has a negligible impact on the pipe 373 
load. The freedom given for the pipe to move upward simulates the mechanism occurring in the natural process in the reallife soil-pipe interaction problem (i.e., naturally, the pipe tends to move towards the ground surface as the failure mechanism seeks the path that mobilises minimal soil resistance). As such, allowing for upward movement is the appropriate and reasonable experimental approach. Note that restricting the pipe in the vertical direction results in a significant increase in $N_{\text {qh }}$, as was shown by Morshed et al. (2020).

In an overall sense, the graphical shape of the observed lateral force versus displacement relationship is similar to those typically observed in previous lateral soil restraint tests (Wijewickreme et al., 2017; Trautmann and O'Rourke, 1985). Initially, the $\bar{F}$ values rise rapidly until the peak normalised soil restraint is reached at a certain displacement, followed by the lateral soil restraint reaching a near-constant value or post-peak drop. The results of the experiments with respect to $N_{\mathrm{qh}}$ and $Y_{\mathrm{p}}$ are detailed in Table 3. Accordingly, the peak dimensionless force $\left(N_{\mathrm{qh}}\right)$ is in the range of 8 to 10 for the tests with the level ground conditions $(\vartheta=0)$. This is consistent with the results reported by Trautmann and O'Rourke (1985) for buried pipes subject to horizontal displacements under level ground conditions. The value of $N_{\mathrm{qh}}$ increases almost twofold when the pipe is displaced in the sloping ground with a grade of $40 \%$. Fig. 6(c) presents $\bar{F}_{h}-\bar{Y}$ response of soilpipe interaction for the slope grades of $-25 \%$ and $-40 \%$ (tests 6 and 7, respectively) where the $N_{\mathrm{qh}}$ is reduced by about $30 \%$, from about 6 to 4 , as the ground slope is decreased from -25\% to $-40 \%$. The results clearly show the significant influence of the ground slope on the ensuing horizontal bearing capacity factor $\left(N_{\mathrm{qh}}\right)$, which can be a key consideration for the design of pipelines traversing sloping ground in mountainous areas, river banks, etc.

Another parameter of value from the force-displacement relations for soil pipe-interaction evaluations is the displacement corresponding to the peak force, commonly called the critical pipe displacement $\left(Y_{\mathrm{p}}\right)$. As per Eq.3, the soil resistance is fully mobilised once $Y_{\mathrm{p}}$ reaches $0.1 \mathrm{D}$ to $0.15 \mathrm{D}$. This is in good agreement with the experimental data. It is also important to understand the test limitations with respect to the value of $Y_{\mathrm{p}}$, which is about 3-5 $\mathrm{cm}$ for a 0.32 -m-diameter pipe. In spite of the time and effort carefully put into the experimental setup as well as for accurate measurement of forces and movements, certain system compliance aspects may still arise that are hard to practically control—such as the uniformity of soil compaction in the immediate vicinity of the pipe, and stretching the displacement measurement string-potentiometer cables through the soil mass. The magnitude of these compliance errors on $Y_{\mathrm{p}}$ is judged to be in the order of 1 to $2 \mathrm{~cm}$. As such, we believe that it is difficult to confidently compare discrepancies in $Y_{\mathrm{p}}$ values from experiments to an accuracy finer than $2 \mathrm{~cm}$. It should also be noted that considering the size of the experiment, this level of accuracy is considered reasonable and should be expected. The reader is referred to Monroy-Concha (2013) and Karimian
(2006) for detailed discussion on the experimental limitation 428 and associated errors.

Table 3. Summary of experimental results

\begin{tabular}{|c|c|c|c|c|}
\hline \multicolumn{3}{|c|}{ Test ID } & \multicolumn{2}{c|}{ Results } \\
\hline Test \# & $\zeta$ & $\vartheta$ & $N_{\mathrm{qh}}$ & $Y_{\mathrm{p}}$ \\
\hline 1 & 1.6 & $25 \%$ & 11.3 & 0.06 \\
2 & 1.6 & $40 \%$ & 15.4 & 0.08 \\
3 & 2.0 & 0 & 8.3 & 0.05 \\
4 & 2.0 & $25 \%$ & 12.8 & 0.1 \\
5 & 2.0 & $40 \%$ & 16 & 0.08 \\
6 & 2.4 & $-40 \%$ & 4.2 & 0.05 \\
7 & 2.4 & $-25 \%$ & 6 & 0.12 \\
8 & 2.4 & 0 & 9.8 & 0.12 \\
9 & 2.4 & $25 \%$ & 13.3 & 0.08 \\
10 & 2.4 & $40 \%$ & 15.5 & 0.15 \\
\hline \multicolumn{4}{|c}{}
\end{tabular}

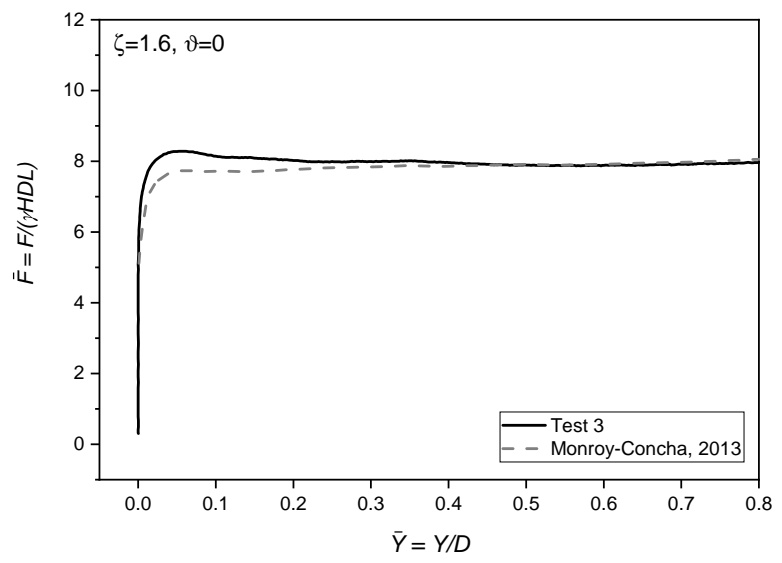

Fig. 5. Test verification-results of test 3 , compared to a similar test from Monroy-Concha (2013)

\section{NUMERICAL STUDY}

The full-scale experimental program successfully illustrated the 430 significance of sloping grounds on the soil-pipe interaction 431 behaviour. However, higher burial depth ratios could not be 432 investigated experimentally due to the physical limitation of 433 the chamber size. Under real-life conditions, there can be 434 cases where a pipeline needs to be buried several metres 435 below the ground surface to meet operational requirements 436 or to traverse certain geological and topographical conditions. $\quad 437$ Therefore, it was considered important to investigate the soil 438 force development in slopes with higher $\zeta$ values.

An FE model is developed using Abaqus/Explicit to 440 investigate the horizontal bearing capacity factor for the burial 441 depth ratios higher than 2.4 under the inclined ground surface 442 condition. The initial stress condition in the soil mass is 443 estimated in a general static step in Abaqus/Standard and 444 then imported into the explicit model as a predefined field 445 from the general static model's output database. The soil-pipe 446 interaction is modelled using the surface-to-surface contact 447 method with penalty constraint formulation as available in 448 

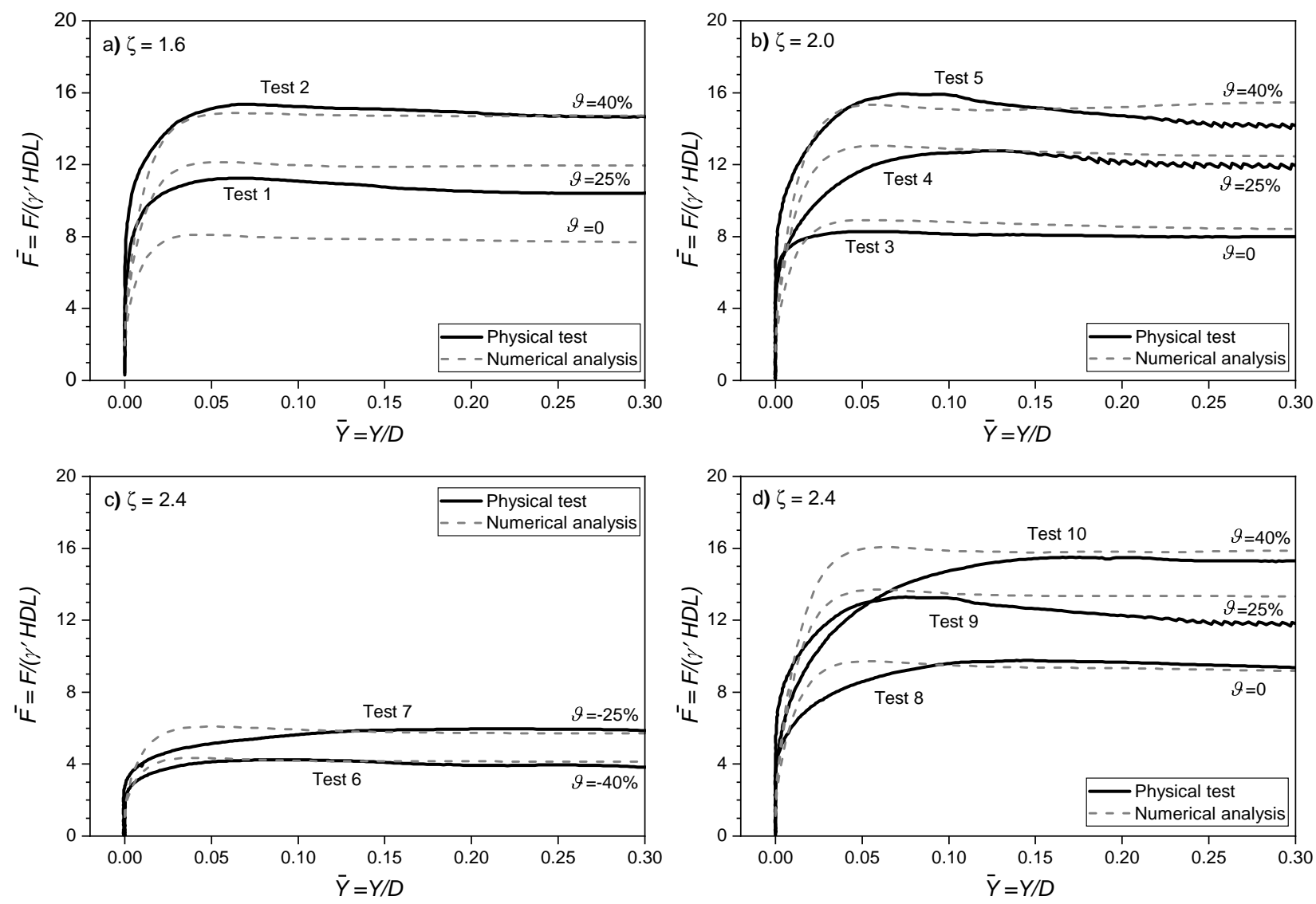

Fig. 6. Lateral force displacement response of soil pipe interaction: comparison between experimental data and numerical results

Abaqus FE software. The soil-pipe interface friction coefficient $(\mu)$ is defined as $\mu=\tan \left(\phi_{\mu}^{\prime}\right)$, where $\phi_{\mu}^{\prime}$ is the interface friction angle that depends on pipe surface roughness and the angle of internal friction $\left(\phi^{\prime}\right)$ of the soil. According to the direct shear tests performed by Karimian (2006), Fraser River sand/sandblasted steel interface friction angle is about 0.85 of the internal friction angle of soil $\left(\phi^{\prime}\right)$. Therefore, the soil-pipe interface friction coefficient, used in the simulations, is $\mu=\tan (0.85 \times$ $\left.\phi^{\prime}\right)=0.81$. Fig. 7 shows the typical FE mesh used in the present study. Note that a mesh sensitivity analysis is conducted, and an approximate mesh size of $2 \mathrm{~cm}$ is found suitable for the analysis. As shown in Fig. 7(a), a structured mesh is generated by zoning the soil domain. Fig. 7(b) shows the FE mesh after the pipe is displaced at the desired location $(\bar{Y}=0.3)$.

The soil is modelled with 4-node bilinear plane-strain quadrilateral elements with reduced integration and hourglass control (i.e. CPE4R in Abaqus FE software). The pipe is modelled as a rigid body according to the experiments. The bottom of the FE domain is restrained from vertical movements, while all the vertical faces are restrained from lateral movements. The physical experiment was conducted at a pipe displacement rate of $2.5 \mathrm{~mm} / \mathrm{sec}$. For numerical simulations, $200 \mathrm{~mm} / \mathrm{sec}$ is used to make the simulations computationally efficient. For all the numerical analyses, kinetic energy (ALLKE) and internal energy (ALLIE) are checked. ALLKE represents a tiny fraction of the ALLIE, 474 showing that the quasi-static condition is satisfied at this 475 loading rate.

\section{Soil model}

The finite element modelling is performed using the classical elastic-perfectly plastic Mohr-Coulomb (MC) soil model available in the Abaqus FE software. The initial stage of the loading is dominated by the elastic behaviour, while the plastic deformation occurs as the applied shear stress exceeds the shear strength of the soil. This mechanism is also observed in the soil-pipe interaction tests: a linear force-displacement response followed by almost a perfectly plastic behaviour after the critical pipe displacement (Fig. 6). The MC model is commonly used to predict the horizontal bearing capacity factor for soil (sand)-pipe interaction with and without modifications (Yimsiri et al., 2004; Guo and Stolle, 2005; Xie, 2008; Daiyan et al., 2011; Jung et al., 2013; Roy et al., 2015). In the MC model, angles of internal friction $\left(\phi^{\prime}\right)$ and dilation $(\psi)$ are given as input, which remain constant during the FE analysis. It is worth noting that for dense sand, both $\phi^{\prime}$ and $\psi$ vary with plastic shear strain and mean effective stress by showing a pre-peak hardening and post-peak softening behaviour (Bolton, 1986; Mitchell and Soga, 2005). As constant values of $\phi^{\prime}$ and $\psi$ are used, the MC model cannot capture the post-peak softening 


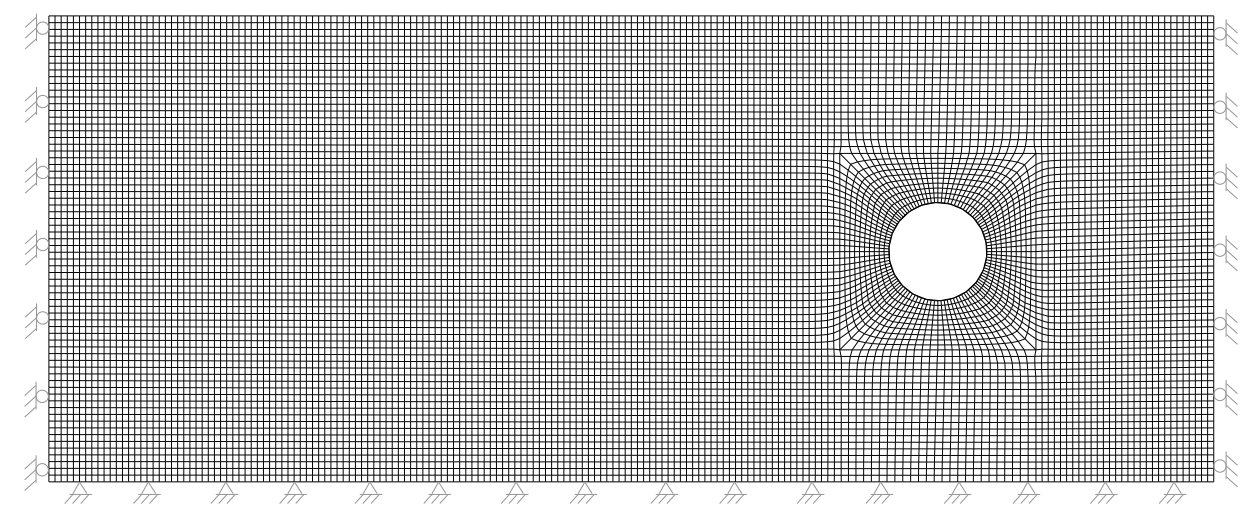

b)

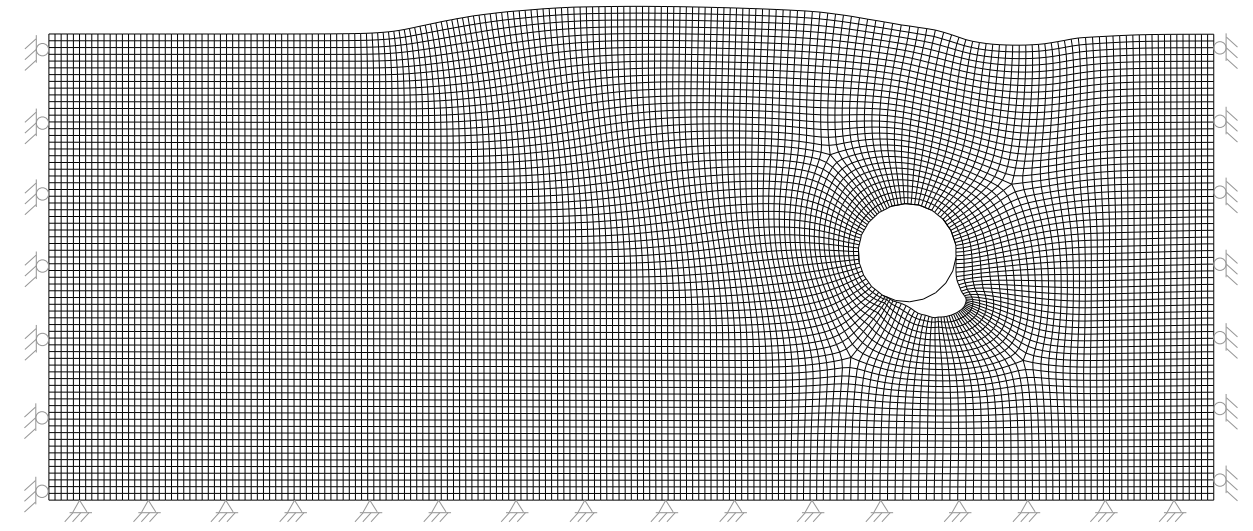

Fig. 7. Typical finite element mesh: (a) before pipe movement; (b) after pipe movement

behaviour of dense sand (Roy et al., 2015, 2018). However, by choosing appropriate equivalent (lower than the peak but higher than the critical) values of $\phi^{\prime}$ and $\psi$ for the plane strain conditions, the MC model can reasonably capture the peak dimensionless force (Yimsiri et al., 2004; Guo and Stolle, 2005; Roy et al., 2018). As the horizontal bearing capacity factor $\left(N_{\mathrm{qh}}\right)$ is the primary focus, the classical MC model is used in the present study. The parameters of the MC model used in this numerical study are selected based upon previous studies on Fraser River sand, which are detailed in Table 4. Specifically, the equivalent soil friction angle of $\phi^{\prime}=46^{\circ}$ is chosen for the numerical simulation by examining the triaxial tests performed by Karimian (2006). Using the critical state friction angle of $\phi_{\text {crit }}=33^{\circ}$ based on the triaxial and hollow cylilnder torsional shear tests conducted by Uthayakumar (1996) and Sivathayalan (2000), the dilation angle for Fraser River sand is estimated to be $\psi=16^{\circ}$ according to $\phi^{\prime}=\phi_{\text {crit }}+0.8 \psi$ from Bolton (1986). It is worth mentioning that other researchers have used similar values of $\phi^{\prime}$ and $\psi$ for soil-pipe interaction simulations using the MC model (Yimsiri et al., 2004; Roy et al., 2018). Note that $\psi$ has a significant effect on $N_{\mathrm{gh}}$ and needs to be selected appropriately. A sensitivity analysis was conducted on the effects of $\psi$ by increasing it from $0^{\circ}$ to $20^{\circ}$ (while keeping $\phi^{\prime}$ constant at $46^{\circ}$ ) resulting in a $25 \%$ increase in $N_{\mathrm{qh}}$. The initial Young's modulus $\left(E_{\mathrm{i}}\right)$ of Fraser River sand is $65 \mathrm{MPa}$, according to Karimian (2006) at the confining stress and sand $\quad 523$ density resembling conditions in these experiments. In an 524 elastic-perfectly plastic model, a secant elastic modulus can 525 be used to estimate the peak force. Using $E_{\mathrm{sec}}=1 / 3 E_{\mathrm{i}}$ as per $\quad 526$ Byrne et al. (1987), a secant modulus of $21 \mathrm{MPa}$ is calculated $\quad 527$ and used in this study.

Table 4. Properties of the Mohr-Coulomb model

\begin{tabular}{|l|l|}
\hline Soil properties & Values \\
\hline Internal friction angle of soil $\left(\phi^{\prime}\right)$ & $46^{\circ}$ \\
Dilation angle $(\psi)$ & $16^{\circ}$ \\
Secant elastic modulus $\left(E_{\text {sec }}\right)$ & $21 \mathrm{MPa}$ \\
Total unit weight of soil $(\gamma)$ & $16 \mathrm{kPa}$ \\
Poisson's ratio $(\rho)$ & 0.3 \\
Soil-pipe interface friction coefficient $(\mu)$ & 0.81 \\
\hline
\end{tabular}

Model calibration, parametric study, and results The numerical model developed in Abaqus/Explicit is first 530 calibrated against one reference test $(\zeta=2.4, \vartheta=0)$ by selecting 531 appropriate soil properties as discussed in the previous section. $\quad 532$ The comparisons of the force-displacement response and the 533 soil deformation mechanism between the numerical simulation 534 and the physical test are presented in Fig. 8(a) and 8(b). A good 535 agreement is achieved in predicting the peak dimensionless 536 force (Fig. 8a) and the soil failure mechanism (Fig. 8b). It is $\quad 537$ 
worth noting that the peak dimensionless force (i.e. horizontal bearing capacity factor $N_{\mathrm{qh}}$ ) is the primary focus of the present study, which is predicted reasonably well with the MC model. More examples of the deformation pattern between the numerical and experimental simulations are presented and discussed in the next section.

Upon calibration of the model with respect to the experiment corresponding to a flat ground surface, a comprehensive parametric study is conducted with 45 simulations including the slope grades of $\vartheta=-40 \%,-25 \%, 0,25 \%, 40 \%$ and the burial depth ratios of $\zeta=1.6,2,2.4,3,4,5,6,7$ and 8 ( $D$ remains constant at $0.32 \mathrm{~m}$ ). The size of the domain in the numerical model was increased for simulations with higher $\zeta$ values such that the results remain unaffected by the model boundaries. The force-displacement responses of the numerical models with associated physical tests $(\zeta=1.6,2.0,2.4)$ are presented in Fig. 6. Similar to the calibrated model response with the physical test, Fig. 6 shows that the present numerical model can successfully predict the peak dimensionless force of all the experiments with less than $10-15 \%$ error

For brevity, the results from numerical simulations for three specific depth ratios $(\zeta=1.6,3.0,7.0)$ are presented in Fig. 9. It can be noted that the force-displacement curves have similar patterns with a linear increase in the soil resistance up to the peak force followed by a plateau response after the critical pipe displacement. The effects of the slope grade on the pipe load are significant for higher depth ratios as well as for shallower conditions (applicable to $1.6<\zeta<8$ investigated herein). Fig. 9 shows that the displacement at the peak load increases with increasing slope grade and depth ratio. This is expected as it takes larger pipe displacement to mobilise soil resistance due to a higher overburden effective stress and larger mobilised soil mass in deeper pipes. According to Fig. 9, the peak soil resistance is mobilised for all cases before the pipe displacement of $0.1 \mathrm{D}$ to $0.15 \mathrm{D}$, which is in agreement with Eq. 3.

\section{SOIL DEFORMATION MECHANISM}

As indicated earlier, the experimental program involved conducting ten full-scale physical modelling experiments. For brevity, photographs obtained from five tests are presented in Fig. 10, which vividly illustrate the effects of the slope grade on the soil failure mechanism. The resultant displacement vectors, obtained numerically, are overlain on the plastic strain contours (from simulation) and presented for tests 6, 7, 8, 9, and 10 beside the photographs from physical tests to assist with the interpretation. For all the five tests $(\zeta=2.4$ and $\vartheta=$ $40 \%,-25 \%, 0,25 \%, 40 \%$ ), the physical soil failure pattern is in good agreement with the deformation vectors and plastic strain contours, obtained numerically in this study. In an overall sense, the soil deformation patterns presented in Fig. 10 are in good agreement with those from previous research such as
Monroy-Concha (2013), di Prisco and Galli (2006) and Zhang and Askarinejad (2019).

Fig. 10 clearly shows that the shear failure surface is 590 primarily dependent on the slope grade with a more elevated 591 failure surface for a steeper slope. This mechanism can be 592 observed from the resultant vectors as the intercept angle of 593 the vectors with the horizontal plane is increased by increasing 594 the slope grade. As stated earlier, the pipe had the freedom to 595 move vertically while being displaced horizontally. According 596 to the study, the vertical displacement of the pipe is also 597 dependent on the slope grade. In test 6 , for example, the 598 ratio of the vertical to the horizontal displacement of the pipe is about $1 / 3$ (see Fig. 10a,b), whereas, in test 10, this ratio is $2 / 3$ (see Fig. 10i,j). Interestingly, similar conclusions can be drawn from the displacement vectors obtained from the numerical models. For example, the soil displacement vector components, vertical to horizontal, have the same ratio of $1 / 3$ and $2 / 3$ in front of the pipe in tests 6 and 10, respectively, according to Fig. 10(b) and Fig. 10(d). Fig. 10(a) shows that the white sand lines placed for visual observation of deformation patterns at the front transparent walls are not distorted in front of the pipe (test 6). It is evident from Fig. 10(b) that the likely reason lies in the intercept angle of the resultant vectors with the horizontal plane. As the intercept angle is gentle for this particular example, it appears that a more substantial deformation is required for producing noticeable distortion in the horizontally placed white sand stripes.

\section{HORIZONTAL BEARING CAPACITY FACTOR}

The horizontal bearing capacity factor, $N_{\mathrm{qh}}$, is one of the 615 key parameters in analysing the pipelines subjected to ground 616 displacements. The value of $N_{\mathrm{qh}}$ can be used to define 617 soil springs for implementation in beam-type FE analysis of 618 pipelines subject to slope movements according to ALA (2005) 619 and PRCI (2017). $N_{\mathrm{qh}}$ is the maximum values of the $\bar{F}_{h}-620$ $\bar{Y}$ curves, as shown in Fig 6 and Fig. 9. $N_{\text {qh }}$ for all the 621 cases, including 45 numerical simulations and ten full-scale 622 physical model tests, are presented in Fig. 11. The experimental 623 results by Trautmann and O'Rourke (1985) and numerical 624 results by Yimsiri et al. (2004) are also plotted for comparison. 625 Results from Zhang and Askarinejad (2019) are also overlain 626 on Fig. 11 for comparison. It is noted that the pipe moves 627 toward the downslope direction in the experiments of Zhang 628 and Askarinejad (2019); therefore, their results are comparable 629 to tests conducted in this research with negative slopes. It 630 is worth mentioning that $N_{\text {qh }}$ can vary with the change in 631 diameter, which was found by Guo and Stolle (2005) and Roy 632 et al. (2018) for the level ground condition. The diameter effect 633 is also expected for the inclined ground surface condition; 634 however, the authors have left this for future studies. 635

It is apparent from Fig. 11 that the horizontal bearing 636 capacity factor $\left(N_{\mathrm{qh}}\right)$, as expected, is an increasing function of 637 the slope grade and burial depth ratio. The solid black lines in 638 

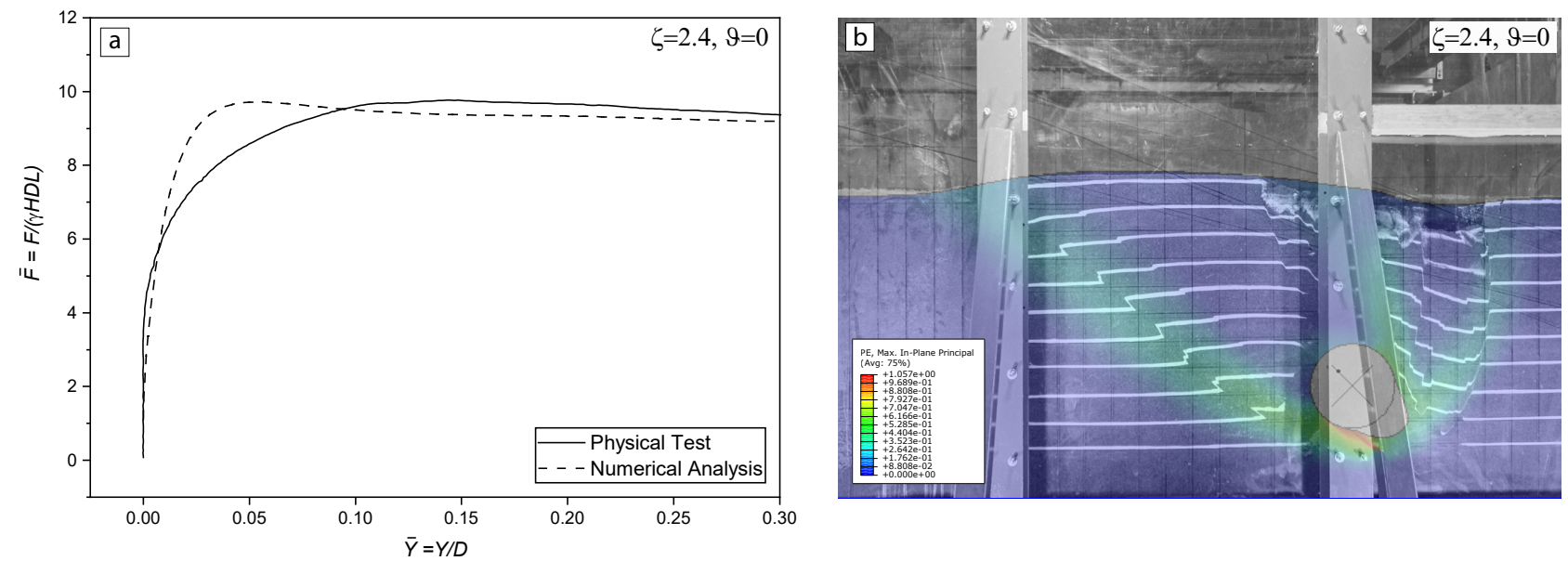

Fig. 8. Calibration of the numerical analysis against a reference test: (a) force-displacement response; (b) The plastic strain from the numerical simulation overlain on a photograph of the deformed soil
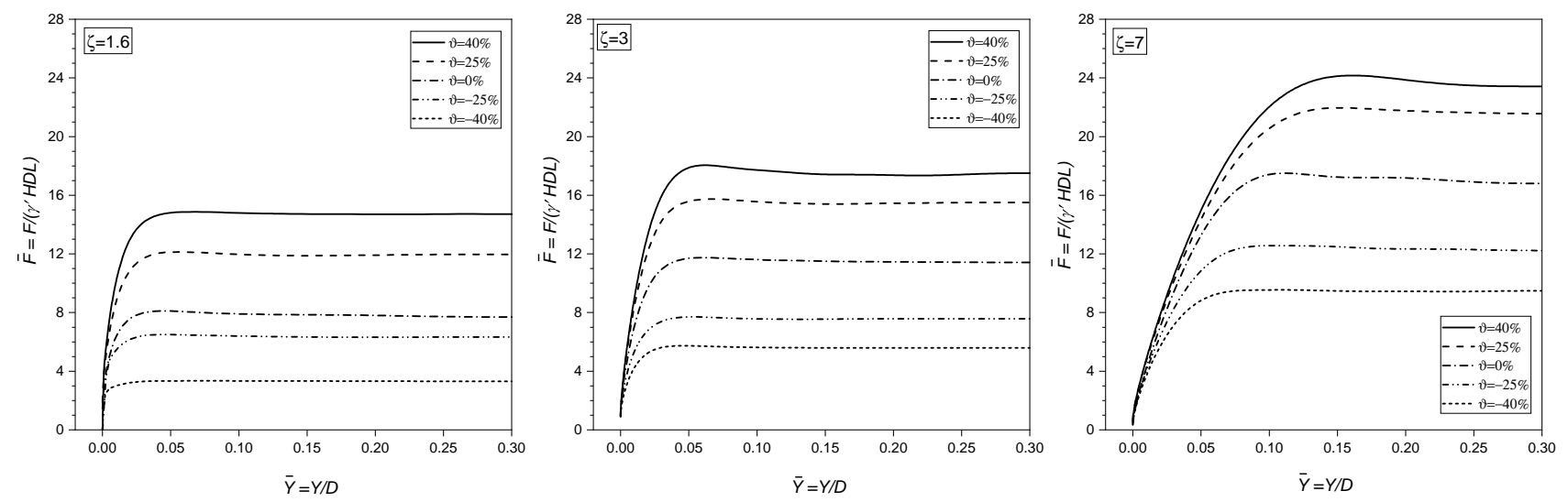

Fig. 9. Force-displacement response of soil-pipe interaction obtained from numerical simulations

this illustration are linear regressions of the numerical data and can be used for $N_{\mathrm{gh}}$ estimation. The study investigates only five slope grades, $-40 \%,-25 \%, 0,25 \%$, and $40 \%$; as such, five lines represent the horizontal bearing capacity factors for each slope case. The lines corresponding to positive slopes (i.e., $\vartheta=25$, $40 \%$ ) can be used to define soil springs within the sliding area. The lines corresponding to negative slopes (i.e., $\vartheta=-25,-40 \%$ ) can be used for defining soil spring outside the landslide area. For example, for a pipe buried at the depth ratio of 5 and slope grade of $25 \%$, it is recommended to use the lines corresponding to $\vartheta=25 \%$ and $\vartheta=-25 \%$ for the sliding area and outside the landslide, respectively. This results in estimating $N_{\mathrm{qh}}$ of 18 for the sliding area and 10 for outside the landslide area. This is about a $30 \%$ increase in $N_{\mathrm{qh}}$ within the sliding area and a $40 \%$ decrease for outside the landslide area, compared to level ground conditions. Increasing the soil load within the sliding area is essential for the safe design of pipelines in sloping grounds. Decreasing the soil load outside the landslide area may provide the opportunity to reach an economical design by distributing the soil loads on a more extended section of the pipe, which in turn prevents the chance of strain localisation, especially around the landslide boundaries where the ground displacements change abruptly. It is to be noted that a lower value of $N_{\text {qh }}$ outside the landslide area is due to the reverse behaviour of soil-pipe interaction in this zone. In a slope movement, the soil loads the pipe within the sliding area while it resists the pipe displacement outside the landslide area. As a result, the amplifying effect of slope grade on $N_{\mathrm{qh}}$ within the sliding area becomes an attenuating effect outside the landslide area. The mechanism of soil-pipe interaction for pipes under thermal loading effects is comparable to conditions developed outside the landslide area; as such, $N_{\mathrm{gh}}$ values corresponding to negative slopes (e.g. $\vartheta=-25 \%$ or $-40 \%$ ) may be considered for such situations.

\section{CONCLUSION}

The current formulations describing soil-pipe interaction have 673 been focused mainly on considering the performance of 674 buried pipelines in level ground subjected to relative ground 675 displacements. The applicability of such formulations becomes 676 questionable when assessing the behaviour of pipelines 677 

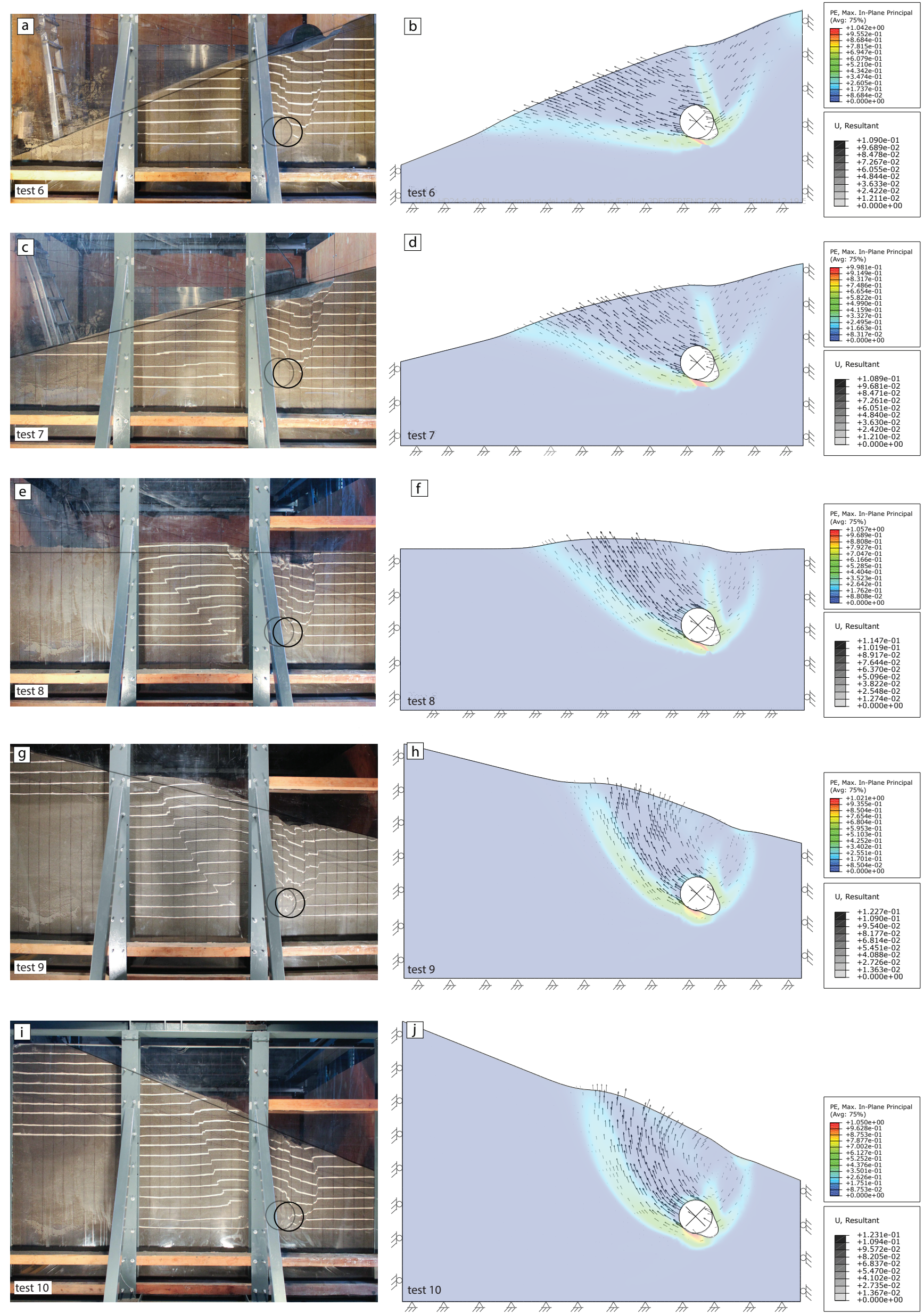

Fig. 10. Soil deformation pattern at $\bar{Y}=0.3$ : (a, c, e, g, i) photographs of the physical test configuration; (b, d, f, h, j) resultant displacement vectors overlain on the plastic strain contours based on the numerical work Prepared using GeotechAuth.cls 


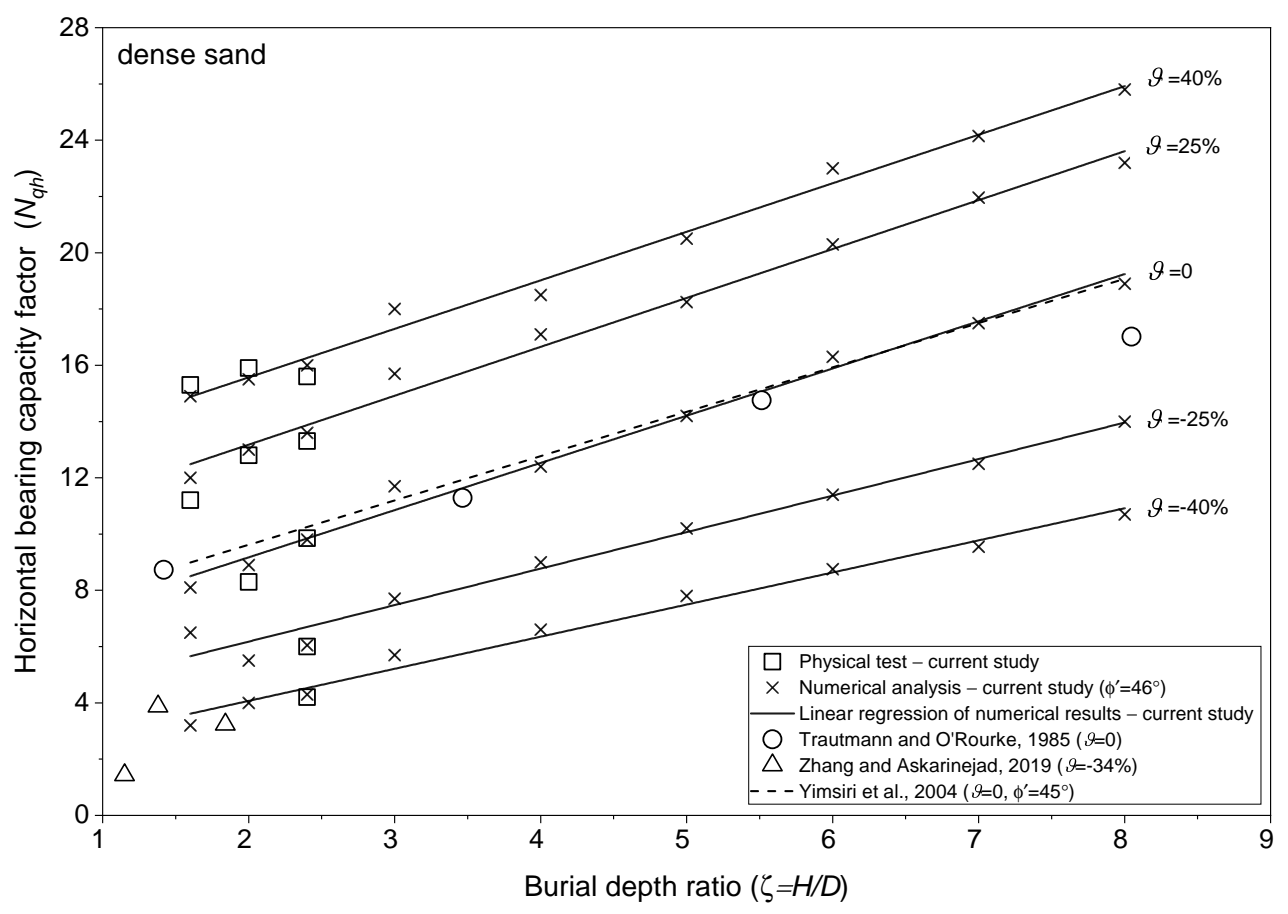

Fig. 11. Horizontal bearing capacity factor versus burial depth ratios

that traverse perpendicular to ground slopes encountered in mountainous areas and river banks, etc. With this background, research was undertaken to study the soil-pipe interaction mechanisms for pipelines buried in sloping ground. Ten fullscale experiments were performed on a $324-\mathrm{mm}$ diameter pipe buried in a sandy slope investigating the lateral soil restraint against pipe displacements. The experimental work was followed by comprehensive numerical analysis to assess pipes having deeper embedment conditions in sloping ground. The development of soil restraint on pipes buried in slopes are defined as a function of two key variables, slope grade and burial depth ratio.

The results demonstrated that the soil restraint is significantly affected by the slope grade in addition to the burial depth ratio, highlighting the importance of accounting for the slope grade in soil-pipe interaction analysis and associated engineering design. The variation of bearing capacity factors, graphically presented as a function of burial depth ratios (i.e., $\zeta$ between 1.6 and 8) and slope grades (i.e., $\vartheta$ between $40 \%$ to $40 \%$ ), could be useful in developing soil springs for evaluating pipeline response in slopes. Further research is required to investigate the effects of slope grade in different soil types and states, such as loose and medium sands. It is also important to understand the soil-pipe interaction behaviour in the longitudinal and vertical directions for sloping grounds in order to fully incorporate the slope grade effects in pipeline modelling and design.

\section{ACKNOWLEDGMENTS}

The authors would like to acknowledge the Natural Sciences and Engineering Research Council of Canada (NSERC), Mathematics of Information Technology and Complex Systems (MITACS), Northern Crescent Incorporation, and the University of Manitoba, Graduate Enhancement of Tri-Council Stipends (GETS) program which collectively funded this project.

\section{NOMENCLATURE}

$\zeta \quad$ burial depth ratio

$\bar{F}_{h} \quad$ dimensionless horizontal load per unit length of pipe

$\bar{Y} \quad$ normalised horizontal displacement of the pipe

$\beta \quad$ slope angle

$\gamma \quad$ total unit weight of soil

$\gamma^{\prime} \quad$ effective unit weight of soil

$\mu \quad$ soil-pipe interface friction coefficient

$\phi_{\text {crit }} \quad$ critical state friction angle

$\phi^{\prime} \quad$ Internal friction angle of soil

$\phi_{\mu}^{\prime} \quad$ soil-pipe interface friction angle

$\psi \quad$ dilation angle

$\vartheta \quad$ slope grade

$C_{\mathrm{u}} \quad$ coefficient of uniformity 724

$D \quad$ outside pipe diameter $\quad 725$

$D_{50} \quad$ average particle size $\quad 726$

$E_{\mathrm{i}} \quad$ initial Young's modulus $\quad 727$

$e_{\max }$ maximum void ratio 728

$e_{\min }$ minimum void ratio 729

$F_{h} \quad$ horizontal load per unit length of pipe 730 
specific gravity

$H \quad$ Distance from ground surface to pipe centre

$N_{\mathrm{qh}} \quad$ horizontal bearing capacity factor

$Y \quad$ transverse pipe displacement

$Y_{\mathrm{p}} \quad$ critical pipe displacement

\section{REFERENCES}

ALA (American Lifeline Alliance) (2005), Guidelines for the design of buried steel pipe. American Society of Civil Engineers.

ASCE (American Society of Civil Engineers) (1984), Guidelines for the seismic design of oil and gas pipeline systems. Committee on Gas and Liquid Fuel Lifelines.

Audibert, J. M. E. and Nyman, K. J. (1978), 'Soil restraint against horizontal motion of pipes', International Journal of Rock Mechanics and Mining Sciences \& Geomechanics Abstracts 15(2), A29.

Bolton, M. D. (1986), 'The strength and dilatancy of sands', Géotechnique 36(1), 65-78.

Burnett, A. J. (2015), Investigation of full scale horizontal pipe-soil interaction and large strain behaviour of sand, $\mathrm{PhD}$ thesis, thesis, Queen's University, Kingston, Ont.

Byrne, P. M., Cheung, H. and Yan, L. (1987), 'Soil parameters for deformation analysis of sand masses', Canadian Geotechnical Journal 24(3), 366-376.

Calvetti, F., Di Prisco, C. and Nova, R. (2004), 'Experimental and numerical analysis of soil-pipe interaction', Journal of geotechnical and geoenvironmental engineering 130(12), 12921299.

Daiyan, N., Kenny, S., Phillips, R. and Popescu, R. (2011), 'Investigating pipeline-soil interaction under axial-lateral relative movements in sand', Canadian Geotechnical Journal 48(11), 1683-1695.

Das, B. M. and Seeley, G. R. (1975), 'Load-displacement relationship for vertical anchor plates', Journal of Geotechnical and Geoenvironmental Engineering 101.

di Prisco, C. and Galli, A. (2006), Soil-pipe interaction under monotonic and cyclic loads: experimental and numerical modelling, in 'Proceedings of the First Euromediterranean Symposium on Advances in Geomaterials and Structures, Hammamet, Tunisia', Vol. 35, Citeseer, pp. 755-760.

Farhadi, B. and Wong, R. C. (2014), Numerical modeling of pipe-soil interaction under transverse direction, in 'International Pipeline Conference', Vol. 46100, American Society of Mechanical Engineers, p. V001T03A021.

Garrison, R. E., Luternauer, J. L., Grill, E. V., MacDonald, R. D. and Murray, J. W. (1969), 'Early diagenetic cementation of recent sands, Fraser River delta, British Columbia', Sedimentology 12(12), 27-46.

Guo, P. and Stolle, D. (2005), 'Lateral pipe-soil interaction in sand with reference to scale effect', Journal of Geotechnical and Geoenvironmental Engineering 131(3), 338-349.

Hansen, J. B. (1961), 'The ultimate resistance of rigid piles against transversal forces', Bulletin 12, Danish Geotech. Institute pp. 1-9.

Hsu, T. W. (1996), 'Soil restraint against oblique motion of pipelines in sand', Canadian Geotechnical Journal 33(1), 180-188.

Hsu, T. W., Chen, Y. J. and Hung, W. C. (2006), 'Soil restraint to oblique movement of buried pipes in dense sand', Journal of Transportation Engineering 132(2), 175-181.

Hsu, T. W., Chen, Y. J. and Wu, C. Y. (2001), 'Soil friction restraint 786 of oblique pipelines in loose sand', Journal of Transportation 787 Engineering 127(1), 82-87.

Jung, J. K., O'Rourke, T. D. and Argyrou, C. (2016), 'Multidirectional force-displacement response of underground pipe in sand', Canadian Geotechnical Journal 53(11), 1763-1781.

Jung, J. K., O’Rourke, T. D. and Olson, N. A. (2013), 'Lateral soil- 792 pipe interaction in dry and partially saturated sand', Journal of 793 Geotechnical and Geoenvironmental Engineering 139(12), 2028- 794 2036.

Karimian, H. (2006), Response of buried steel pipelines subjected to longitudinal and transverse ground movement, $\mathrm{PhD}$ thesis, University of British Columbia.

Katebi, M., Maghoul, P. and Blatz, J. (2019), 'Numerical analysis of pipeline response to slow landslides: case study', Canadian Geotechnical Journal 56(12), 1779-1788.

Katebi, M., Wijewickreme, D., Maghoul, P. and Roy, K. (2020), Effects of slope grade on soil-pipe interaction: Full-scale experiments, in 'International Pipeline Conference', Vol. 84454, American Society of Mechanical Engineers, p. V002T02A010.

Kondner, R. L. (1963), 'Hyperbolic stress-strain response: cohesive soils', Journal of the Soil Mechanics and Foundations Division 89(1), 115-144.

Kostyukov, V. D. (1967), 'Distribution of the density of sand in the sliding wedge in front of anchor plates', Soil Mechanics and Foundation Engineering 4(1), 12-13.

Mitchell, J. K. and Soga, K. (2005), Fundamentals of soil behavior, 812 Vol. 3, John Wiley \& Sons, New York.

Monroy-Concha, M. (2013), Soil restraints on steel buried pipelines crossing active seismic faults, $\mathrm{PhD}$ thesis, University of British Columbia.

Morshed, M. A., Roy, K. and Hawlader, B. (2020), 'Modeling of buried pipelines in dense sand for oblique movement in vertical-lateral plane', Journal of Pipeline Systems Engineering and Practice 11(4), 04020050.

Murray, E. J. and Geddes, J. D. (1989), 'Resistance of passive inclined anchors in cohesionless medium', Géotechnique 39(3), 417-431.

Neely, W. J., Stuart, J. C. and Graham, J. (1973), 'Failure loads of vertical anchor plates in sand', Journal of Soil Mechanics \& Foundations Div 99(Proc. Paper 9980).

Nyman, K. J. (1984), 'Soil response against oblique motion of pipes', Journal of Transportation Engineering 110(2), 190-202.

O'Rourke, M., Gadicherla, V. and Abdoun, T. (2005), 'Centrifuge modeling of PGD response of buried pipe', Earthquake Engineering and Engineering Vibration 4(1), 69-73.

Ovesen, N. K. (1964), 'Anchor slabs, calculation methods and model tests', Bulletin 16, 39.

Ovesen, N. K. and Strømann, H. (1972), Design method for vertical 833 anchor slabs in sand, in 'Performance of earth and earth-supported 834 structures', ASCE, p. 1481.

PRCI (Pipeline Research Council International) (2017), Pipeline 836 Seismic Design and Assessment Guideline. Catalogue No: PR-268- 837 134501-R01.

Robert, D., Soga, K. and O'Rourke, T. (2016), 'Pipelines subjected to 839 fault movement in dry and unsaturated soils', International Journal 840 of Geomechanics 16(5), C4016001.

Rowe, R. K. and Davis, E. H. (1982), 'The behaviour of anchor plates 842 in sand', Géotechnique 32(1), 25-41.

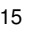

7 843

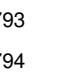

\section{.}

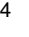

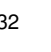
.

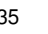

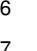

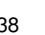

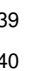

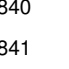
. 
Roy, K., Hawlader, B., Kenny, S. and Moore, I. (2015), 'Finite element modeling of lateral pipeline-soil interactions in dense sand', Canadian Geotechnical Journal 53(3), 490-504.

Roy, K., Hawlader, B., Kenny, S. and Moore, I. (2018), 'Lateral resistance of pipes and strip anchors buried in dense sand', Canadian Geotechnical Journal 55(12), 1812-1823.

Sivathayalan, S. (2000), Fabric, initial state and stress path effects on liquefaction susceptibility of sands, $\mathrm{PhD}$ thesis, University of British Columbia.

Smith, J. E. (1962), Deadman anchorages in sand, Technical report, Naval Civil Engineering Lab Port Hueneme Calif.

Tian, Y. and Cassidy, M. J. (2011), 'Pipe-soil interaction model incorporating large lateral displacements in calcareous sand', Journal of Geotechnical and Geoenvironmental Engineering 137(3), 279-287.

Trautmann, C. H. (1983), Behavior of pipe in dry sand under lateral and uplift loading, PhD thesis, Cornell Univ., Ithaca, NY.

Trautmann, C. H. and O'Rourke, T. D. (1985), 'Lateral forcedisplacement response of buried pipe', Journal of Geotechnical Engineering 111(9), 1077-1092.

Uthayakumar, M. (1996), Liquefaction of sands under multi-axial loading, $\mathrm{PhD}$ thesis, University of British Columbia.

Wijewickreme, D., Karimian, H. and Honegger, D. (2009), 'Response of buried steel pipelines subjected to relative axial soil movement', Canadian Geotechnical Journal 46(7), 735-752.

Wijewickreme, D., Monroy, M., Honegger, D. G. and Nyman, D. J. (2017), 'Soil restraints on buried pipelines subjected to reversefault displacement', Canadian Geotechnical Journal 54(10), 14721481.

Xie, X. (2008), Numerical analysis and evaluation of buried pipeline response to earthquake-induced ground fault rupture, $\mathrm{PhD}$ thesis, Rensselaer Polytechnic Institute.

Yimsiri, S., Soga, K., Yoshizaki, K., Dasari, G. and O’Rourke, T. D. (2004), 'Lateral and upward soil-pipeline interactions in sand for deep embedment conditions', Journal of Geotechnical and Geoenvironmental Engineering 130(8), 830-842.

Zhang, W. and Askarinejad, A. (2019), 'Behaviour of buried pipes in unstable sandy slopes', Landslides 16(2), 283-293. 